\title{
DNA Integrity Estimated via the Comet Assay Reflects Oxidative Stress and Competitive Disadvantage in Developing Birds
}

\author{
Bibiana Montoya ${ }^{1, *}$ \\ Diego Gil ${ }^{2}$ \\ Mahara Valverde ${ }^{3}$ \\ Emilio Rojas ${ }^{3}$ \\ Lorenzo Pérez-Rodríguez ${ }^{4, \star}$ \\ ${ }^{1}$ Centro Tlaxcala de Biología de la Conducta, Universidad \\ Autónoma de Tlaxcala, Tlaxcala, Mexico; ${ }^{2}$ Departamento de \\ Ecología Evolutiva, Museo Nacional de Ciencias Naturales, \\ Consejo Superior de Investigaciones Científicas, Madrid, \\ Spain; ${ }^{3}$ Instituto de Investigaciones Biomédicas, Universidad \\ Nacional Autónoma de México, Mexico City, Mexico; \\ ${ }^{4}$ Instituto de Investigación en Recursos Cinegéticos, Consejo \\ Superior de Investigaciones Científicas, Universidad de \\ Castilla-La Mancha, Junta de Comunidades de Castilla-La \\ Mancha, Ciudad Real, Spain
}

Accepted 7/7/2020; Electronically Published 8/11/2020

\begin{abstract}
Increases in DNA degradation have been detected in numerous situations in which organisms are exposed to pollutants. However, outside of the ecotoxicological literature, few studies have investigated whether there exists important variation in DNA integrity in free-living, healthy animals. Using the alkaline version of the comet assay to estimate DNA integrity in blood samples, we aimed to evaluate whether DNA integrity during early life is associated with nestlings' age, body mass, withinbrood status, and oxidative stress using nestlings from a wild population of spotless starlings (Sturnus unicolor) as a model. We found important levels of variation in DNA integrity, suggesting the possibility that DNA integrity may have implications for offspring fitness. DNA integrity was dependent on the developmental stage, being lower at hatching than at the end of the nestling period. DNA integrity was also negatively related to the levels of oxidative damage at hatching and positively associated with wing length at fledging. In addition, position within the size hierarchy of the brood at fledging explained differences in DNA integrity, with higher levels in core than in marginal nestlings. Finally, despite extensive within-individual variation along nestling's age, we found DNA integrity during early life to be moderately repeatable within broods. Hence,
\end{abstract}

*Corresponding authors; email: bibianac.montoyal@uatx.mx, lorenzoperez rodriguez@gmail.com.

Physiological and Biochemical Zoology 93(5):384-395. 2020. (C) 2020 by The University of Chicago. All rights reserved. 1522-2152/2020/9305-19134\$15.00. DOI: $10.1086 / 710703$
DNA integrity in early life appears to be mainly affected by environmental factors, such as natural stressors. Our results suggest that measuring the variation in DNA integrity may be a fruitful approach for the assessment of individual fitness in natural populations and can be applied to studies in developmental biology and ecology.

Keywords: antioxidants, early development, DNA damage, brood hierarchies.

\section{Introduction}

Developmental conditions are influential in shaping individuals' fitness prospects, affecting a wide range of traits with both short- and long-term effects (Lindström 1999; Monaghan 2007). Proximate mechanisms mediating these effects are still elusive, although oxidative stress (i.e., the imbalance between prooxidants and antioxidants in the organism in favor of the former) has been proposed as a candidate to play such a proximate role (Alonso-Álvarez et al. 2007; Monaghan 2007). During development, the intensified metabolic rates and high cell turnover that accompany growth may increase the production of reactive oxygen species (ROS). This overproduction of ROS can be harmful for the developing individual because of the relative immaturity of some components of its antioxidant system (Mangel and Munch 2005; Criscuolo et al. 2008; Dmitriew 2011; but see Salin et al. 2015). ROS are required for cellular signaling (Hurd and Murphy 2009; Dickinson and Chang 2011), but they can also trigger harmful reactions for biomolecules when they remain unneutralized (Beckman and Ames 1998; Finkel and Holbrook 2000). The action of oxidative stress has been proposed to link harsh developmental conditions to detrimental effects in DNA integrity by promoting telomere attrition (i.e., telomeres are noncoding repetitive DNA caps at the end of eukaryotic chromosomes; Geiger et al. 2012; Nettle et al. 2013, 2015; Boonekamp et al. 2014; Cram et al. 2017; Criscuolo et al. 2019; Gil et al. 2019; but for the link between oxidative stress and telomere shortening in vivo, see Boonekamp et al. 2017; Reichert and Stier 2017; Pérez-Rodríguez et al. 2019) and DNA fragmentation (Noguera et al. 2011). Although the impact of harsh developmental conditions on telomere attrition has received great attention in past years, factors influencing more general forms of DNA damage in developing individuals have been sparsely studied in healthy, wild populations.

DNA repair mechanisms can deal with most of the damage that appears in the lifetime of an individual (Iyama and 
Wilson 2013). However, some lesions may persist and accumulate with age, leading to detrimental consequences at different levels: cells, physiological systems, and individual performance (Lord and Ashworth 2012). Evidence for these effects in humans and laboratory animal models is provided by the extensive biomedical research on aging and cancer (e.g., Su 2006; David et al. 2007; Altieri et al. 2008; Swenberg et al. 2011; Mandal et al. 2011). Interestingly, under normal conditions, organisms may suffer up to 50,000 lesions in their DNA daily, and these are considered to be mostly induced by ROS, which are unavoidable by-products of aerobic metabolism (Coussens and Werb 2002; von Sonntag 2006; Swenberg et al. 2011; Dizdaroglu and Jaruga 2012). Therefore, a malfunction in the capacity of the individual to deal with this daily challenge may affect senescence rate and, consequently, reproductive and survival prospects (López-Otín et al. 2013). Even though the links between ROS and life-history traits have received considerable attention during the last two decades, the use of DNA fragmentation as an estimate of physiological state in healthy, wild animals has been explored only recently.

Methods to measure DNA damage can be classified in two general groups. Methods in the first group rely on the quantification of certain compounds - or the by-products of their alteration - whose levels are known to vary concurrently with the magnitude of the DNA damage, such as 8-oxodG (8-oxo7,8-dihydro-2'-deoxyguanosine) and 8-oxoGua (8-oxo-7,8dihydroguanine; Dizdaroglu et al. 1993). Methods in the second group attempt to directly estimate the damage occurred at different scales, for example, at specific bases (e.g., apurinicapyrimidinic sites; Loeb and Preston 1986), at specific sequences (e.g., telomere shortening; Blackburn and Epel 2012; Muraki et al. 2012), and along the strands (e.g., DNA fragmentation; Ostling and Johanson 1984). Within this second category, one of the most widely used tools in biomedicine and ecotoxicology is the comet assay. Also known as the single-cell gel electrophoresis assay, this technique measures DNA damage through the quantification of breaks in single and double DNA strands, alkali-labile sites (including apurinic-apyrimidinic sites), and incomplete excision-repair sites (Ostling and Johanson 1984; Singh et al. 1988; Collins et al. 2008; fig. 1). However, its use to evaluate variation in DNA integrity between individuals of healthy, wild organisms has been very limited. The few studies that have been done in birds that are apparently unexposed to toxicological agents suggest that DNA integrity is sensitive to variation in the quality of nutritional resources (Freeman-Gallant et al. 2011) and exposure to an immune challenge (Meitern et al. 2013) or stressful conditions (Gormally et al. 2019). Similarly, in wild birds exposed to toxic compounds, DNA integrity positively correlates with body condition during development (Baos et al. 2006; Fenstad et al. 2014; Galván et al. 2014). Therefore, measuring DNA integrity as a proxy for genomic stability may be an interesting approach to estimate an individual's physiological status under a wider framework linking ecological processes with biochemical mechanisms. This may ultimately translate into useful applications for research in the fields of ecology and developmental biology.
Here, using the comet assay, we aimed to evaluate whether DNA integrity during early life varies throughout development and whether it reflects the individual's body condition, exposure to competitive disadvantages with siblings, and oxidative status. We used nestlings of the spotless starling (Sturnus unicolor) as a model. In this altricial passerine, within-brood size asymmetries often arise during the nestling period (Gil et al. 2008). In birds, these brood asymmetries can impose significant viability costs to lower-rank brood mates (i.e., marginal nestlings) compared with higher-rank siblings (i.e., core nestlings; Forbes et al. 1997). Proximally, this can be manifested in a lower body condition at fledging, higher oxidative stress levels, or higher telomere attrition (e.g., Hall et al. 2010; Nettle et al. 2015), perhaps mediated through increases in sibling competition (Neuenschwander et al. 2003). Considering these effects and the links suggested between adverse conditions and higher DNA fragmentation in adult, wild birds, we expected (i) an overall positive association between nestling body mass or size and DNA integrity, (ii) lower DNA integrity in marginal fledglings compared with core fledglings of the same brood, and (iii) lower DNA integrity in nestlings experiencing higher oxidative stress at hatching (i.e., lower antioxidant capacity and/or higher oxidative damage).

\section{Methods}

\section{Study System and Data Collection}

This study was conducted in May 2018, in a free-living nest box population of spotless starlings located at Soto del Real, Madrid, Spain $\left(40^{\circ} 45^{\prime} 15^{\prime \prime} \mathrm{N}, 3^{\circ} 47^{\prime} 0^{\prime \prime} \mathrm{W}\right)$. Details of our yearly monitoring protocol have been provided elsewhere (Muriel et al. 2015b; Gil et al. 2019). This breeding population is located in a dehesa ecosystem covered by a deciduous woodland of oak (Quercus pyrenaica) and ash (Fraxinus angustifolius). The study site is adjacent to a protected area (Guadarrama National Park), and both the study site and the surrounding areas that make up the home range of the spotless starlings are exploited for extensive cattle grazing. This population shows extremely low levels of organohalogenated contaminants (among the lowest reported in a large-scale study on starlings; Eens et al. 2013), which allows us to consider it a nonexposed population. The spotless starling is a relatively long-lived, colonial, and sedentary passerine that exhibits a facultative polygynous breeding system, breeds in natural tree holes and artificial cavities, and shows sexual dimorphism (Moreno et al. 1999; Jimeno and Gil 2015). In our study population, most pairs lay two consecutive clutches per breeding season, although we included only first broods in this study. In this population, modal clutch size is $4.72 \pm 0.57$ (mean $\pm \mathrm{SE}$ ) eggs, fledging success for completed clutches is $78 \%$, and the nestling period lasts about 21 or $22 \mathrm{~d}$ (López-Rull et al. 2007; B. Montoya, D. Gil, M. Valverde, E. Rojas, and L. Pérez-Rodríguez, unpublished data).

Two different sets of nests were selected to address the aims of this study. In the first set, within individuals, nests were followed through the nestling period, while in the second set, within broods, broods were visited only at fledging. Both sets of nests were randomly distributed across our study site, and the 

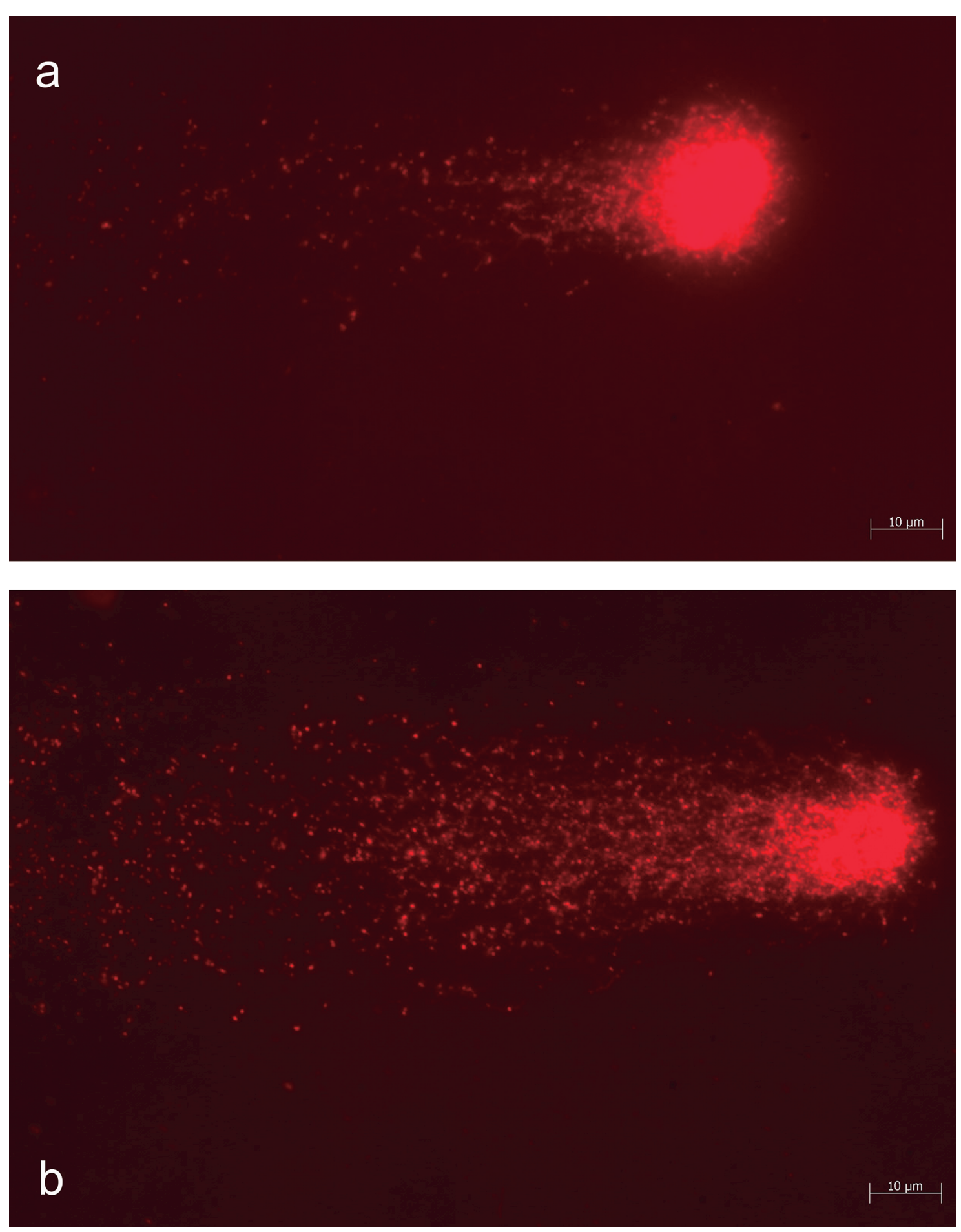

Figure 1. Intensity of the comet tail relative to the head reflects the amount of broken DNA (i.e., broken DNA strands migrate from the comet head). Panel $a$ shows an example of a nucleoid with $92.04 \%$ of DNA in the head and $7.96 \%$ of DNA in the tail. Panel $b$ presents an example of a nucleoid with $57.53 \%$ of DNA in the head and $42.47 \%$ of DNA in the tail.

only difference between them was the sampling schedule applied and the fact that nests selected for the within-broods analyses included at least one nestling that could be clearly identified as marginal (see below). Using the within-individuals set $(n=25$ nests), we aimed to explore the changes in DNA integrity with age and the relationship of DNA integrity with oxidative stress at hatching and with body mass during nestling growth. When the hatching date approached, we visited nests every $4 \mathrm{~h}$ to make sure we sampled chicks shortly after hatching. We randomly selected one to three hatchlings per brood 
(mean $\pm \mathrm{SE}=2.11 \pm 0.42)$ to be included in the withinindividuals set. Hatchlings $(n=46)$ were weighed $( \pm 0.01 \mathrm{~g})$ and individually marked by distinct down cutting, allowing for individual recognition in subsequent visits. The time elapsed between hatching and sampling was assessed using two categories based on the level of wetness of the down (Muriel et al. 2015a): chicks found wet-damp were categorized as hatched $<2 \mathrm{~h}$ before the visit, whereas chicks found dry were categorized as hatched $>2 \mathrm{~h}$ before the visit. Additionally, a $40-\mu \mathrm{L}$ blood sample was taken from the jugular vein. Blood samples were kept cold until they arrived at the laboratory facilities (within $5 \mathrm{~h}$ ). An aliquot of whole blood was diluted in Synth-a-Freeze (Gibco, Life Technologies, New York) to a concentration of 35 million cells $/ \mathrm{mL}$. The remaining blood was centrifuged at $10,000 \mathrm{rpm}$ for $5 \mathrm{~min}$ at $4^{\circ} \mathrm{C}$, and the plasma was separated from the red blood cells (RBCs). Both the plasma and the whole blood diluted in Synth-a-Freeze were stored at $-80^{\circ} \mathrm{C}$ until analyses were performed. We visited the same nests when nestlings were $6 \mathrm{~d}$ old, and we weighed ( $\pm 0.1 \mathrm{~g}$ ) them and individually marked them with numbered aluminum rings. We did not collect blood during this second visit. Finally, when nestlings were $14 \mathrm{~d}$ old, we recorded fledglings' weight ( $\pm 0.1 \mathrm{~g})$, tarsus length $( \pm 0.1 \mathrm{~mm})$, and wing length $( \pm 1 \mathrm{~mm})$ and collected a second blood sample of ca. $30 \mu \mathrm{L}$ from the brachial vein using heparinized capillaries. The samples were transported to the laboratory facilities as described above and diluted in Synth-a-Freeze to the same cell concentration described above. All nestlings were blood sampled within $3 \mathrm{~min}$ after being retrieved from the nest to control for the potential effect of handling stress on DNA fragmentation and oxidative stress parameters.

Using the within-broods set $(n=17$ nests), we aimed to explore the effect of the within-brood size hierarchy on DNA integrity at $14 \mathrm{~d}$ of age. These broods were located in the same areas of the colony and hatched on the same dates and were therefore exposed to the same ecological conditions as the withinindividuals set. In each of these broods, we selected the marginal nestling (i.e., the sibling with the lowest body mass within the brood) and randomly selected one of the core siblings (i.e., siblings with average body mass within the brood). Both siblings were blood sampled (ca. $30 \mu \mathrm{L}$ from the brachial vein using heparinized capillaries), and blood samples were processed, as described above, for DNA fragmentation analysis only (sampling for oxidative stress biomarkers was not possible at this sampling event because of logistical constraints). In addition, we recorded fledglings' weight, tarsus length, and wing length as described above. At $14 \mathrm{~d}$ of age, core and marginal siblings from the same brood strongly differed in body mass $\left(\beta=-14.72 \pm 2.39, F_{1,16}=37.85\right.$, $P<0.001)$, tarsus length $\left(\beta=-2.12 \pm 0.67, F_{1,16}=10.11, P<\right.$ $0.01)$, and wing length $\left(\beta=-9.88 \pm 2.29, F_{1,16}=18.84, P<\right.$ 0.001; see table A1).

\section{DNA Integrity Analysis-Comet Assay}

The comet assay, also known as the single-cell gel electrophoresis assay, estimates DNA damage through the quantification of breaks in single and double DNA strands, alkali- labile sites (including apurinic-apyrimidinic sites), and incomplete excision-repair sites (Ostling and Johanson 1984; Singh et al. 1988; Collins et al. 2008; fig. 1). This test uses the propensity of broken fragments to migrate during an electrophoretic assay to estimate the proportion of nonmigrated DNA (comet head) to migrated DNA (comet tail) to quantify DNA integrity. DNA integrity was estimated in RBCs from the whole-blood samples of hatchlings and fledglings following Rojas et al. (1999). Unlike mammalian RBCs, avian erythrocytes are nucleated, thus allowing measures of damage to DNA integrity in blood samples (Scanes 2015). Samples were conserved in Syntha-Freeze, a liquid cryopreserving medium. Briefly, samples were defrosted for up to $60 \mathrm{~s}$ at $36^{\circ} \mathrm{C}$ in a water bath. After this, $200 \mu \mathrm{L}$ of phosphate-buffered saline was added to the cells, and the mixture was centrifuged at 7,000 rpm for $30 \mathrm{~s}$. Supernatant was completely discarded, and 50 or $100 \mu \mathrm{L}$ of $0.5 \%$ low-melting point agarose (LMPA) was added depending on, respectively, whether the cells' pellet was unnoticeable or clearly distinguishable. Beforehand, we prepared microscope slides by prelayering them with $150 \mu \mathrm{L}$ of $0.5 \%$ regular agarose and left them to dry at $36^{\circ} \mathrm{C}$. Over these slides, we added $20 \mu \mathrm{L}$ of the LMPA-cells solution and two additional layers of LMPA, covering the gel with a coverslip and maintaining the slide for $10 \mathrm{~min}$ at $4^{\circ} \mathrm{C}$ between each layer. Coverslips were removed, and slides were transferred into a cold lysis solution at $4^{\circ} \mathrm{C}(2.5 \mathrm{M} \mathrm{NaCl}, 100 \mathrm{mM} \mathrm{Na} 2$ ethylenediaminetetraacetic acid [EDTA], $10 \mathrm{mM}$ Tris-base, $\mathrm{pH}$ 10, adding $1 \%$ Triton, $10 \%$ dimethyl sulfoxide in fresh) and kept at $4^{\circ} \mathrm{C}$ for $1 \mathrm{~h}$. After lysis, slides were placed in an electrophoresis chamber filled with electrophoresis solution $(10 \mathrm{~N} \mathrm{NaOH}, 200 \mathrm{mM}$ EDTA, pH > 13) for $20 \mathrm{~min}$, and after this, electrophoresis was performed for $20 \mathrm{~min}(23 \mathrm{~V}, 300 \mathrm{~mA} ; 0.8 \mathrm{~V} / \mathrm{cm})$. After electrophoresis, slides were sequentially washed with neutralization solution (0.4 M Tris-HCl, pH 7.5) and 96\% ethyl alcohol and then left to dry for $>15 \mathrm{~min}$. Slides were dyed with $3 \mu \mathrm{L}$ of SYBR Safe (1:3 Tris-borate-EDTA buffer diluted) and analyzed under an Olympus BX51 (×20 magnification) fluorescence microscope using the comet assay software (ver. 5.0; Kinetic Imaging, Andor, United Kingdom). We measured 100 nucleoids per slide to determine the percentages of head and tail DNA. Because of the strategy used to calculate these values (i.e., intensity of fluorescence in the comet tail relative to the head; fig. 1), the percentages of head and tail DNA are perfectly complementary measures. Each sample was processed and quantified in duplicate. Coefficient of variation (CV) between replicates was 3.98\%.

\section{Oxidative Stress Analyses}

Oxidative stress was evaluated in plasma samples using one biomarker of oxidative damage (reactive oxygen metabolites [ROMs]) and one biomarker of antioxidant capacity (OXY). Details on reagent volumes and procedures have been described in detail elsewhere (Pérez-Rodríguez et al. 2015, 2019). ROMs, as quantified by the d-ROMs assay kit (Diacron, Grosetto, Italy), are mostly composed of lipid hydroperoxides, which have been extensively used as biomarkers of oxidative damage (Costantini 2016). We diluted $15 \mathrm{~mL}$ of plasma in a $200-\mu \mathrm{L}$ solution 
containing $0.01 \mathrm{M}$ acetic acid/sodium acetate buffer ( $\mathrm{pH} 4.8)$ and $N, N$-diethyl- $p$-phenylenediamine as chromogen. This mixture was then incubated for $75 \mathrm{~min}$ at $37^{\circ} \mathrm{C}$ to allow metabolites to react with an alkyl-substituted aromatic amine solubilized in the chromogen, producing a complex whose color intensity is directly proportional to the concentration of metabolites. After incubation, the absorbance was read with a Synergy HT multimode microplate reader (BioTek Instruments) at $546 \mathrm{~nm}$. Concentration of ROMs ( $\mathrm{mg} \mathrm{H}_{2} \mathrm{O}_{2} / \mathrm{dL}$ plasma) was calculated by comparing the absorbance of samples with a calibration standard supplied with the kit.

OXY of plasma samples was evaluated using the OXYadsorbent assay (Diacron, Grosetto, Italy). This colorimetric test evaluates the nonenzymatic OXY of plasma by quantifying the ability of plasma samples to cope with the oxidant action of hypochlorous acid ( $\mathrm{HOCl}$; an oxidant of pathologic relevance in biological systems), using $N, N$-diethyl-p-phenylenediamine as chromogen. For OXY assays, plasma samples were diluted in distilled water at a ratio of $1: 100$. A $200-\mu \mathrm{L}$ aliquot of $\mathrm{HOCl}$ solution was incubated with $10 \mu \mathrm{L}$ of the diluted plasma samples for $10 \mathrm{~min}$ at $37^{\circ} \mathrm{C}$. The same relative volumes were used for the reference standard supplied with the kit and blank (i.e., water). Then $5 \mu \mathrm{L}$ of the same chromogen solution used for the ROMs determination was added. An alkyl-substituted aromatic amine solubilized in the chromogen was oxidized by the residual $\mathrm{HOCl}$ and transformed into a pink derivative. The intensity of the colored complex, which is inversely related to the antioxidant power, was measured at $546 \mathrm{~nm}$ with the same microplate reader mentioned above. Measurements are expressed as micromoles of $\mathrm{HOCl}$ neutralized.

\section{Statistical Analyses}

Statistical analyses were performed in $\mathrm{R}$ version 3.5.3 ( $\mathrm{R} \mathrm{De}$ velopment Core Team 2019). To account for the nature of the data (i.e., proportions), the percentage of DNA in the comet head (fig. 1), as a proxy for DNA integrity, was arcsine square root transformed before analyses (Sokal and Rolf 1981). We used the within-individuals data set to evaluate withinindividual differences in DNA integrity between the ages of 1 and $14 \mathrm{~d}$. We fitted a mixed model including percentage of DNA in the comet head as response variable, individual's age as a fixed effect, hatching date as a covariate, and individual's identity nested in nest identity as a random factor. The association between body mass and DNA integrity at hatching was evaluated by fitting a mixed model including DNA integrity at day 1 as response variable, body mass at hatching and hatching date as covariates, time after hatching as a fixed factor $(>2 \mathrm{~h}$ or $<2 \mathrm{~h}$ ), and nest identity as a random factor. To evaluate the association between DNA integrity and body mass at fledging, a model including DNA integrity at day 14 as response variable and body mass at day 14 and hatching date as covariates was fitted. To test for a relationship between DNA integrity and oxidative stress at hatching, we fitted a model including DNA integrity as response variable; ROMs, OXY, and hatching date as covariates; time after hatching as a fixed factor; and nest identity as a random factor. We evaluated whether oxidative stress at hatching was associated with DNA integrity at fledging by fitting a model including DNA integrity at day 14 as response variable; oxidative status at day 1 (ROMs and OXY), daily growth rate (i.e., difference between the body mass at day 14 and at hatching divided by the exact number of days elapsed between initial and final measurements), and hatching date as covariates; and nest identity as a random factor. Finally, we explored variables explaining the change in DNA integrity from hatching to fledging (difference between DNA integrity at hatching and fledging) by fitting a model including change in DNA integrity as response variable (after correcting for regression to the mean; Verhulst et al. 2013); DNA integrity at hatching, oxidative status at hatching (ROMs and OXY), daily growth rate (calculated as explained above), and hatching date as covariates; and nest identity as a random factor.

Using the within-broods data set, we evaluated the association between position within the nest hierarchy and DNA integrity by fitting a mixed model including DNA integrity at day 14 as response variable, position within the nest hierarchy as a fixed factor (core vs. marginal), hatching date as a covariate, and nest identity as a random factor.

All final models were obtained by backward deletion of nonsignificant terms. $P$ values were calculated through the Satterthwaite correction using the $\mathrm{R}$ package lmerTest (Kuznetsova et al. 2015). Adjusted repeatabilities were estimated, controlling for the time lapsed after hatching and the age category, using the R package rptR (Nakagawa and Schielzeth 2010). Sample sizes may vary slightly among analyses because not all variables could be analyzed for all nestlings and sampling events as a result of limitations imposed by the sample volume.

\section{Results}

Percentage of DNA in the comet head at hatching and fledging varied between $50 \%$ and $88 \%$ (mean $\pm \mathrm{SE}=70.9 \% \pm 5.8 \%$; fig. 2). DNA integrity had a moderate repeatability in withinbroods hatchlings $(R=54 \%, 95 \%$ confidence interval $[\mathrm{CI}]=$ $15 \%-78 \%, P=0.003)$, but it had a much lower, nonsignificant repeatability in within-broods fledglings $(R=31 \%, 95 \% \mathrm{CI}=$ $0 \%-69 \%, P=0.15)$ and in within-individuals fledglings sampled at different ages (i.e., 1 and $14 \mathrm{~d}$ after hatching; $R=25 \%$, $95 \% \mathrm{CI}=2 \%-44 \%, P=0.09$ ). Levels of ROMs and OXY were repeatable within broods at hatching (ROMs: $R=85 \%, 95 \%$ $\mathrm{CI}=80 \%-89 \%, P<0.001$; OXY: $R=90 \%, 95 \% \mathrm{CI}=85 \%-$ 92\%, $P<0.001)$.

\section{Within-Individuals Data Set}

Individual chicks had a lower percentage of DNA in the comet head at hatching than at fledging $(\beta=0.39 \pm 0.08$, $F_{1,58.84}=22.99, P<0.001$; fig. $\left.3 a\right)$. At the day of hatching, DNA integrity was not associated with body mass, time since hatching, or hatching date (table 1). 
At fledging, variation in DNA integrity was not associated with body mass or hatching date (table 1). However, if we used wing length as an index of size instead of body mass, we found that fledglings with larger wings had a higher percentage of DNA in the comet head $\left(\beta=0.47 \pm 0.15, F_{1,22.98}=9.73, P=\right.$ 0.005; fig. $3 b)$. This relationship with DNA integrity was not found for tarsus length $\left(F_{1,32.03}=0.93, P=0.34\right)$.

When we explored the relationship between DNA integrity and oxidative status at hatching, we found that the percentage of DNA in the comet head was negatively related to the levels of ROMs in hatchlings (table 2; fig. 4a). Hatching date in this model significantly explained variation in DNA integrity, but no association between DNA integrity and OXY was found at this age (table 2; fig. 4b). Variation in DNA integrity at fledging was not explained by the levels of ROMs or OXY at hatching, the hatching date, or the daily growth rate (table 2 ). The change in DNA integrity from hatching to fledging was not associated with DNA integrity or levels of ROMs or OXY at hatching, the daily growth rate, or the hatching date (table 2).

\section{Within-Broods Data Set}

At fledging, core nestlings showed a higher percentage of DNA in the comet head than their marginal brood mates $(\beta=$ $-4.29 \pm 1.43, F_{1,32}=8.96, P=0.006$; fig. $5 a$ ). In this data set, there was a positive association between percentage of DNA in the comet head and nestling's body mass, pooling core and marginal nestlings together $\left(\beta=0.18 \pm 0.07, F_{1,28.4}=7.18\right.$, $P=0.01$; fig. $5 b$ ). However, the percentage of DNA in the comet head was better predicted by the difference in body mass between siblings than by the absolute body mass of the focal chick

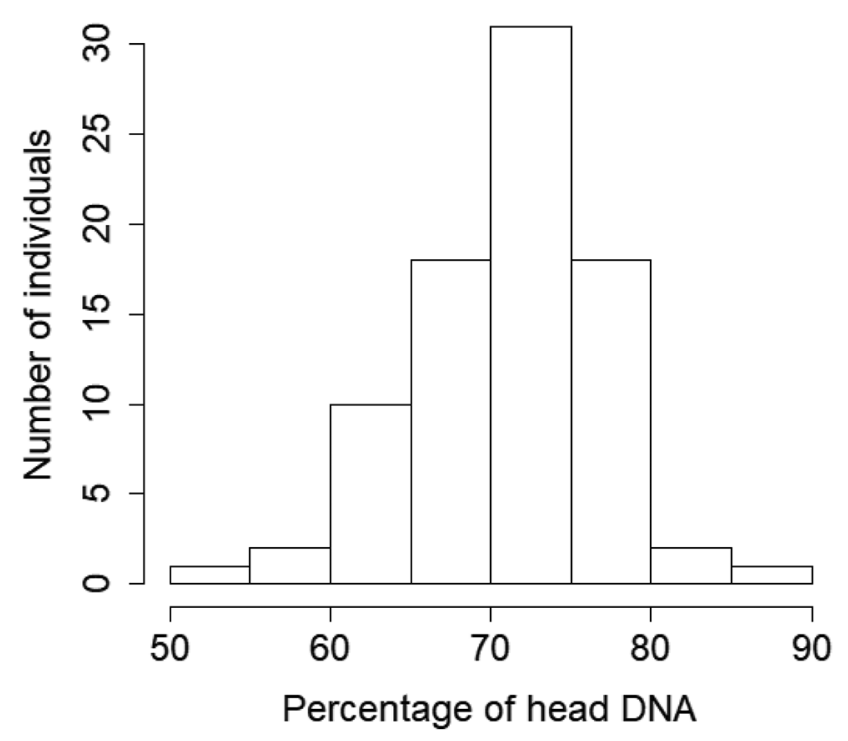

Figure 2. Variation in DNA integrity found in nestling spotless starlings. DNA integrity was measured as the percentage of nonmigrated DNA (i.e., head DNA) using the comet assay in its alkaline version.
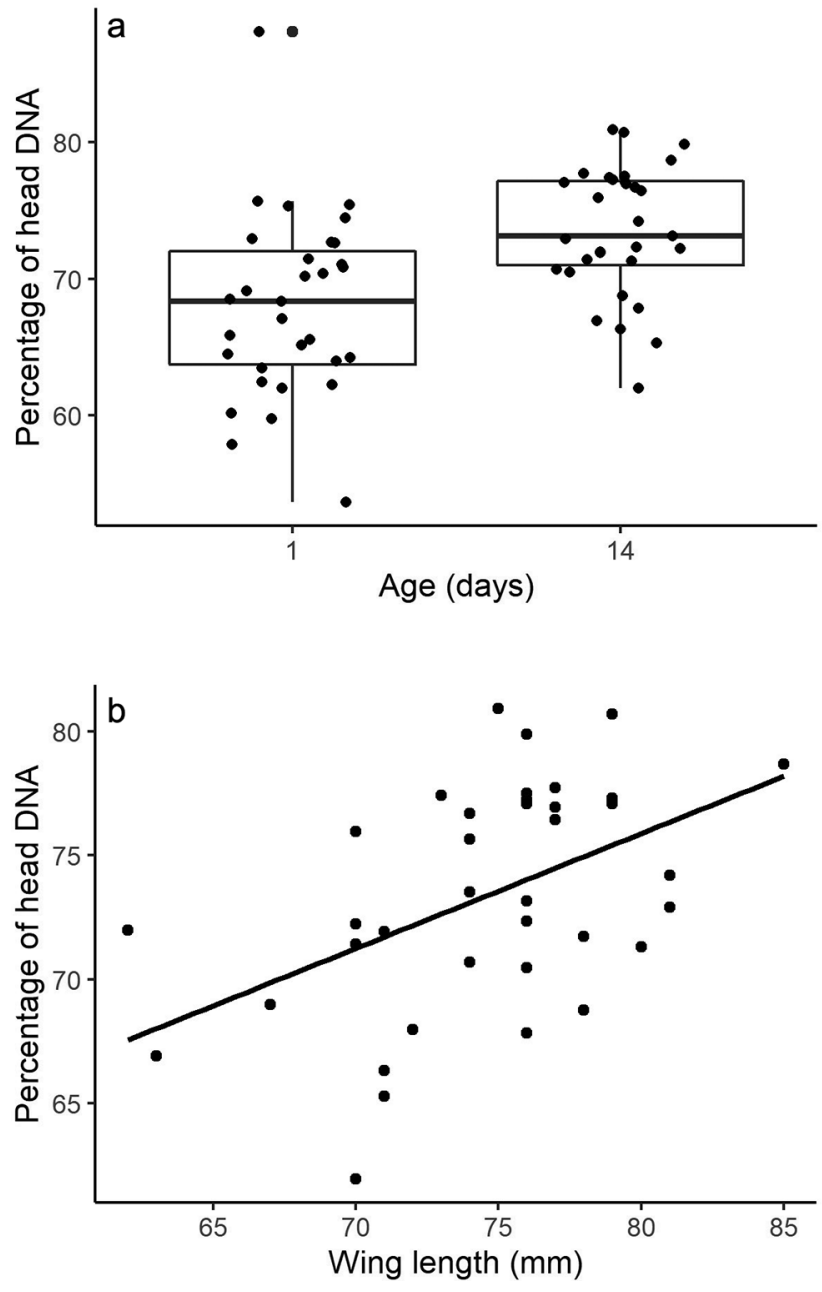

Figure 3. Relationship of DNA integrity with nestlings' age class and body size in the spotless starling. Panel $a$ shows within-individual differences in DNA integrity at hatching and fledging (i.e., 1 and $14 \mathrm{~d}$ old, respectively). Boxes indicate interquartile ranges, the horizontal line in each box indicates the median, and the points show all of the values included in the analyses. Panel $b$ presents the percentage of head DNA in relation to wing length at age $14 \mathrm{~d}$. DNA integrity was measured as the percentage of head DNA using the comet assay in its alkaline version.

(difference in body mass between siblings: $\beta=0.14 \pm 0.04$, $F_{1,32}=12.94, P=0.001$; focal chick body mass: $F_{1,14}=0.05$, $P=0.94)$. In other words, lower nestling DNA integrity was associated with larger within-brood differences in mass (fig. $5 b$ ).

\section{Discussion}

Despite the fact that, in the average organism, the amount of DNA that may be damaged by the action of metabolic byproducts is estimated to be as large as 50,000 lesions per day (Friedberg et al. 2006; Swenberg et al. 2011; Lomax et al. 2013), few studies have evaluated the variation in DNA integrity in 
Table 1: Relationship of DNA integrity during early life (estimated as percentage of DNA in the comet head) with individual's body mass, hatching date, and time after hatching

\begin{tabular}{|c|c|c|c|c|c|c|c|c|c|c|}
\hline & \multicolumn{5}{|c|}{ At hatching } & \multicolumn{5}{|c|}{ At $14 \mathrm{~d}$ old } \\
\hline & Estim & SE & $F$ & ddf & $P$ & Estim & SE & $F$ & ddf & $P$ \\
\hline Body mass & -.11 & 1.10 & .01 & 23.32 & .92 & .14 & .11 & 1.65 & 34.17 & .21 \\
\hline Hatch date & -2.01 & 1.24 & 2.62 & 22.93 & .12 & -1.25 & 1.07 & 1.38 & 21.86 & .25 \\
\hline Time after hatch & -1.28 & 1.96 & .43 & 36.06 & .52 & $\ldots$ & $\ldots$ & $\ldots$ & $\ldots$ & $\ldots$ \\
\hline
\end{tabular}

Note. $n=46$ individuals sampled at hatching, and $n=37$ sampled at $14 \mathrm{~d}$ after hatching; individuals sampled belonged to 25 and 23 different nests, respectively. Percentage of DNA in the comet head was arcsine square root transformed, generalized linear mixed models with normal error distribution were fitted, and nest identity was included as a random factor. Estim = estimate; ddf $=$ denominator degrees of freedom.

free-living, nonexposed organisms. In this study, we assessed a free-living population of spotless starlings that were apparently unexposed to toxicological agents and found significant levels of variation in DNA integrity in nestlings and patterns that suggest that variation in this measurement has implications for offspring fitness. We found that hatchlings had lower DNA integrity than fledglings. In addition, DNA integrity was negatively related to the levels of oxidative damage at hatching and positively associated with wing length at fledging. Furthermore, marginal nestlings had lower DNA integrity than their siblings occupying central positions. Finally, despite extensive withinindividual variation along nestling's age, we found DNA integrity during early life to be moderately repeatable within broods.

\section{DNA Integrity and Nestlings' Age}

We found that DNA integrity was strongly dependent on the developmental stage, being lower at hatching than at the end of the nestling period. Hatchlings could have presented lower DNA integrity possibly as a result of the sudden exposure to new environmental conditions after hatching. Alternatively, hatch- lings may show a reduced capacity for cell-repairing mechanisms (Udroiu and Sgura 2016; but see Heuser et al. 2008).

\section{DNA Integrity and Nestlings' Body Size}

DNA integrity was unrelated to nestlings' body mass at hatching and fledging but was positively associated with fledglings' wing length in our within-individuals data set. This result runs counter to our prediction that body mass should be positively associated with DNA integrity. The lack of an association between body mass and DNA integrity may be explained by the fact that the individuals included in this sample were in relatively homogeneous good condition. Low levels of variation in this measurement would account for the lack of a relationship. Nestlings in this within-individuals data set showed a remarkably low CV in body mass (9\%), lower, for instance, than that exhibited by birds included in the analysis comparing core versus marginal brood mates (within-broods data set; $15 \%$ ). Indeed, within this second set of birds (core vs. marginal brood mates), we did find a positive association between body mass and DNA integrity in fledglings. Interestingly, despite the lack of an association between body mass and DNA integrity in the fledglings of the within-individuals data set, we did find a positive association between wing length and

Table 2: Relationship between DNA integrity during early life (estimated as percentage of DNA in the comet head) and oxidative stress at hatching (reactive oxygen metabolites [ROMs] or antioxidant capacity [OXY])

\begin{tabular}{|c|c|c|c|c|c|c|c|c|c|c|c|c|c|c|c|}
\hline & \multicolumn{5}{|c|}{ At hatching } & \multicolumn{5}{|c|}{ At $14 \mathrm{~d}$ old } & \multicolumn{5}{|c|}{ Change } \\
\hline & Estim & SE & $F$ & ddf & $P$ & Estim & SE & $F$ & ddf & $P$ & Estim & SE & $F$ & ddf & $P$ \\
\hline ROMs & -1.06 & .41 & 6.75 & 24.43 & .02 & .56 & .45 & 1.55 & 29.46 & .22 & .59 & .39 & 2.29 & 21.49 & .14 \\
\hline OXY & .03 & .03 & 1.18 & 33.91 & .28 & .02 & .03 & .48 & 24.34 & .49 & -.01 & .03 & .12 & 22.16 & .14 \\
\hline Hatch date & -3.13 & .96 & 10.64 & 13.20 & .006 & -1.28 & 1.12 & 1.32 & 20.35 & .26 & .23 & 1.59 & .02 & 21.58 & .88 \\
\hline $\begin{array}{c}\text { Time after } \\
\text { hatch }\end{array}$ & -2.60 & 2.08 & 1.56 & 30.48 & .22 & $\ldots$ & $\ldots$ & $\ldots$ & $\ldots$ & $\ldots$ & $\ldots$ & $\ldots$ & $\ldots$ & $\ldots$ & $\ldots$ \\
\hline Growth rate & $\ldots$ & $\ldots$ & $\ldots$ & $\ldots$ & $\ldots$ & 1.84 & 1.40 & 1.73 & 29.95 & .20 & 2.63 & 1.53 & 2.96 & 28.24 & .10 \\
\hline $\begin{array}{l}\text { DNA } \\
\text { integrity } \\
\text { at hatching }\end{array}$ & $\ldots$ & $\ldots$ & $\ldots$ & $\ldots$ & $\ldots$ & $\ldots$ & $\ldots$ & $\ldots$ & $\ldots$ & $\ldots$ & .04 & .13 & .10 & 21.09 & .76 \\
\hline
\end{tabular}

Note. $n=46$ individuals sampled at hatching, and $n=37$ sampled at $14 \mathrm{~d}$ after hatching; individuals sampled belonged to 25 and 23 different nests, respectively. Percentage of DNA in the comet head was arcsine square root transformed, generalized linear mixed models with normal error distribution were fitted, and nest identity was included as a random factor. Estim = estimate; $\mathrm{ddf}=$ denominator degrees of freedom. 

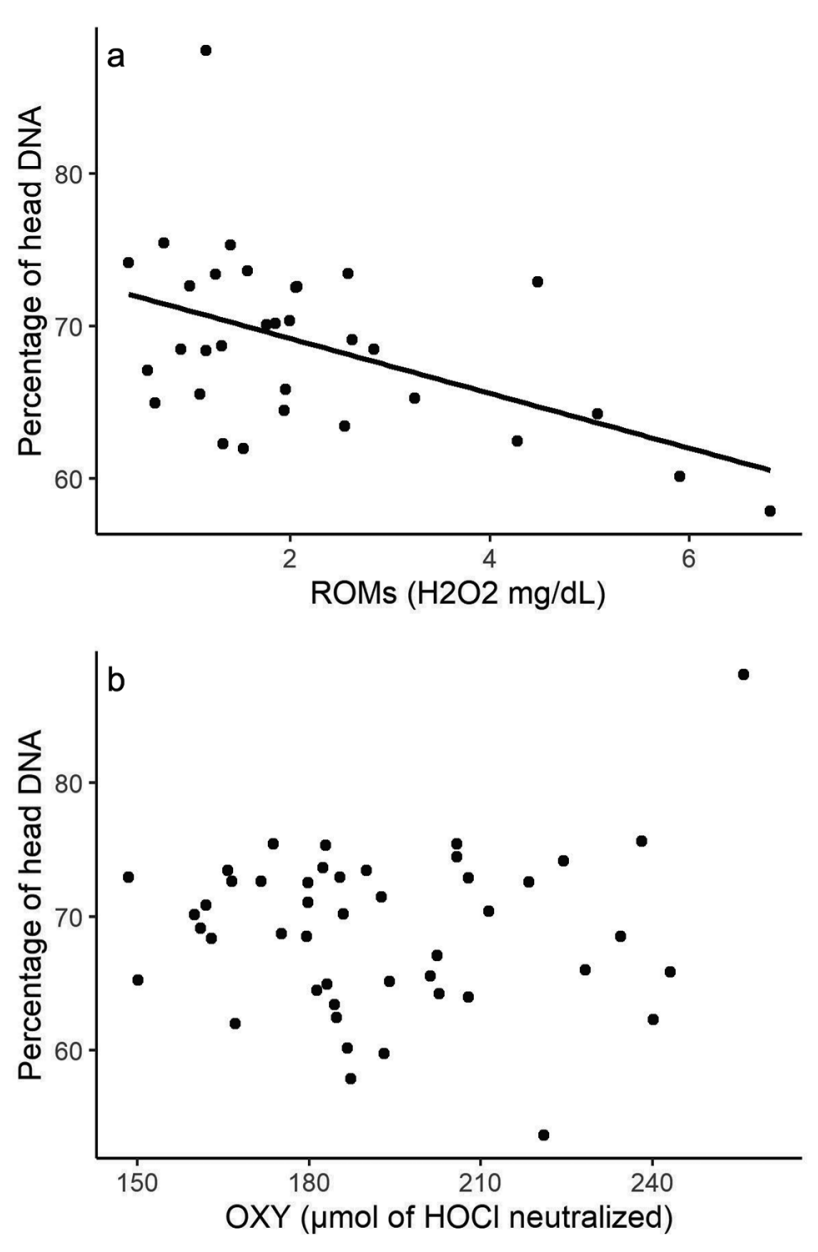

Figure 4. Relationship between oxidative markers and DNA integrity at hatching in spotless starlings. Panel $a$ shows the association between the level of reactive oxygen metabolites (ROMs; $\mathrm{H}_{2} \mathrm{O}_{2} \mathrm{mg} / \mathrm{dL}$ ) in plasma and DNA integrity. Panel $b$ presents the percentage of head DNA in relation to antioxidant capacity (OXY; $\mu \mathrm{mol}$ of $\mathrm{HOCl}$ neutralized) levels. DNA integrity was measured as the percentage of head DNA using the comet assay in its alkaline version.

DNA integrity. Hence, it could be argued that, at this developmental stage in passerines, whereas mass and tarsus length have attained almost asymptotical values, wing length is still growing (Starck and Ricklefs 1998). This would indicate that wing length at this stage is a relevant index of current growth. Thus, a feasible alternative explanation is that the decreased DNA integrity found in nestlings with shorter wings may reflect poorer developmental conditions that extended the period of wing growth. The explanations presented above would not be mutually exclusive, given that individuals in the within-individuals data set were all in relatively good condition to grow appropriately or to catch up. In contrast, marginal individuals in the within-broods data set showed markedly poorer developmental conditions. These results suggest that harsh developmental conditions are required to observe concurrent changes in DNA integrity, as has been suggested to occur with telomere erosion (Criscuolo et al. 2019).

\section{DNA Integrity and Within-Brood Hierarchy}

At fledging, core siblings, which are better fed, had higher DNA integrity than their marginal brood mates. This result supports our prediction and suggests that nest asymmetries are an important source of stress in marginal nestlings. Accordingly, other studies have found that, in altricial species, marginal siblings require longer time to grow flight feathers (Bitton et al. 2006) and have higher corticosterone levels (Núñez de la Mora et al. 1996), higher oxidative stress (Hall et al. 2010), increased telomere erosion (Nettle et al. 2013, 2015), and lower immune response (Martín-Vivaldi et al. 2006). Studies show that once in adulthood, these individuals may present lower fledging rates (Griebel and Dawson 2018) and lower reproductive success (Drummond and Rodríguez 2013). Interestingly, in
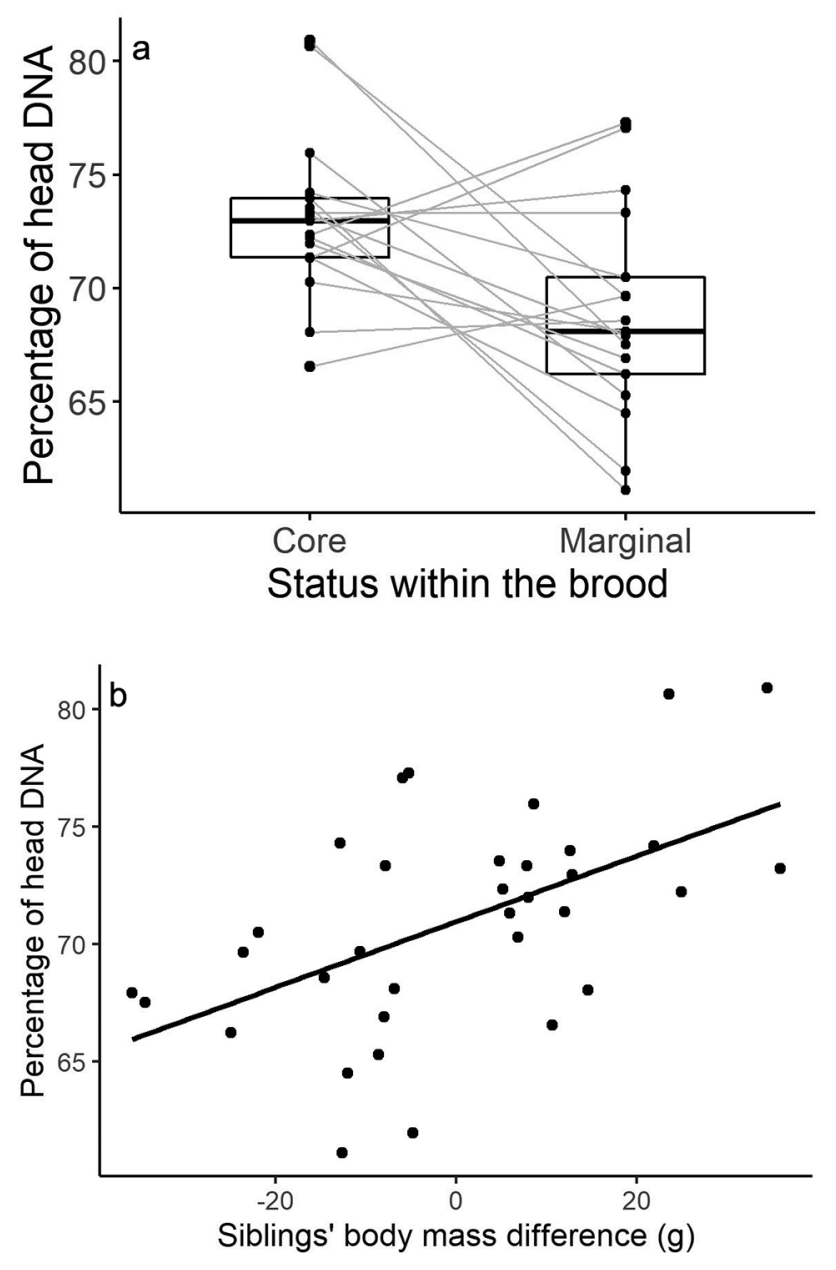

Figure 5. DNA integrity and within-brood differences in body mass in spotless starlings. Panel $a$ shows differences in DNA integrity between core and marginal fledglings ( $14 \mathrm{~d}$ old). Boxes indicate interquartile ranges, and the horizontal line in each box indicates the median. Gray lines connect the core and marginal siblings sampled in each brood. Panel $b$ presents the percentage of head DNA in relation to the magnitude of within-brood differences in body mass between marginal and core nestlings. DNA integrity was measured as the percentage of head DNA using the comet assay in its alkaline version. 
our study, DNA integrity was better predicted by the magnitude of the difference in body mass between marginal and core siblings than by the absolute body mass of the focal chick. This provides additional support for the idea that social stress linked to withinbrood asymmetries has detrimental effects on the physiological condition of marginal individuals (Neuenschwander et al. 2003; Salomons et al. 2009; Nettle et al. 2013, 2015). Moreover, this result shows that DNA integrity is not only linked to individual mass but also to stressful conditions, as recently suggested (Gormally et al. 2019).

\section{DNA Integrity and Oxidative Stress}

When we explored the potential proximate links between DNA integrity and oxidative stress in hatchlings, we found, in support of our prediction, that higher levels of ROMs were associated with lower DNA integrity. At hatching, individuals are particularly exposed to the risk of suffering oxidative chain reactions fueled by the by-products of the oxidation of polyunsaturated fatty acids accumulated during embryo development (Surai 1999, 2002; Surai et al. 2016). Consistent with this, we found that hatchlings had lower DNA integrity than fledglings. During the hatchling stage, individuals' antioxidant systems are still immature (Metcalfe and Alonso-Alvarez 2010), and therefore antioxidant defenses rely mostly on molecules transferred by the mother to the egg (Surai 2002). However, we did not find an association between hatchlings' DNA integrity and OXY. Interestingly, estimates of DNA integrity, as well as levels of ROMs and OXY, at hatching were repeatable within broods, suggesting an important influence of genetic or maternal effects affecting these parameters. In any case, within-brood repeatability of DNA integrity was lower than that of ROMs and OXY. This may indicate that there are other sources of variation, different from those shared in a common rearing environment, that affect DNA integrity. DNA integrity was measured from RBCs, which have a half-life in birds estimated to be on average $39.7 \pm 3.3 \mathrm{~d}$ (Beuchat and Chong 1998; Scanes 2015). Hence, the fact that DNA integrity increases from hatching to fledging indicates that DNA fragmentation in RBCs may be repaired, and therefore individuals may differ not only in the rate of exposure to DNA fragmentation but also in their capacity to repair this type of damage. Oxidative stress in erythrocytes may compromise oxygen delivery, accelerate aging rate (Mohanty et al. 2014), and even impact immune function (Passantino et al. 2007; Morera et al. 2011; Anderson et al. 2018). Therefore, optimal functioning of RBCs is likely to be crucial to maintaining vital processes. However, these results raise important questions. To what extent does DNA damage in RBCs compromise their function? What is the timeframe in which a given DNA damage in erythrocytes can affect an individual's physiology, considering the short half-life of this cellular type? Is there an association between DNA damage in RBCs and other cellular types with lower renewal rates? Future research should address these questions that are raised by our findings.
In conclusion, this study shows that factors that compromise development, such as a stressful social context within the nest, may promote erythrocyte DNA fragmentation in organisms that are apparently unexposed to toxicological agents. This result, combined with the moderate within-brood repeatability found (in the absence of within-individual repeatability) at hatching but not at fledging, suggests that DNA integrity is likely to be more influenced by maternal effects than by genetic factors. From a proximate perspective, exposure to ROMs appears to be linked to decreased DNA integrity. Our results suggest that erythrocyte DNA integrity may be used to assess the impact of harsh environmental conditions during early development in wild animals. Future studies should evaluate the sensitiveness of this variable to different types of stressors, the persistence of its effects, and its usefulness as a reliable correlate of fitness-related traits during adulthood.

\section{Acknowledgments}

We thank Lucía Arregui for her assistance during sample processing and two anonymous reviewers, whose comments improved the manuscript considerably. Jaime Muriel, Stefania D’Arpa, Cristiano Gala, Hannah Van Noort, and João H. de Oliveira helped during fieldwork. Permission to conduct the study was granted by the Consejería de Medio Ambiente (Comunidad de Madrid). This research complies with the current laws of Spain and the Animal Behavior Guidelines for experimentation with animals. This work was partially supported by a fellowship from Programa para el Desarrollo Profesional Docente para el Tipo Superior (PRODEP, UATLX-PTC-129) granted to B.M., an Acceso al Sistema Español de Ciencia, Tecnología e Innovación postdoctoral contract to L.P.-R., and the research projects PGC2018-099596-B-I00 (cofinanced by the European Regional Development Fund) and CGL201783843-C2-1-P from the Spanish Ministry of Science, Innovation, and Universities. We declare no conflict of interests. B.M., D.G., and L.P.-R. designed the study. D.G. and L.P.-R. performed the fieldwork. B.M. and L.P.-R. ran the laboratory analyses. B.M. performed the statistical analyses and drafted the manuscript. All co-authors contributed critically to the preparation of later versions of the manuscript and gave final approval for publication.

\section{APPENDIX}

Table A1: Morphometrical differences between core and marginal nestlings of the same nest at $14 \mathrm{~d}$ of age

\begin{tabular}{lrrrrr}
\hline & \multicolumn{2}{c}{ Core nestlings } & & \multicolumn{2}{c}{ Marginal nestlings } \\
\cline { 2 - 3 } & Mean & SE & & Mean & \multicolumn{1}{c}{ SE } \\
\hline Body mass $(\mathrm{g})$ & 82.68 & 1.55 & & 67.96 & 2.35 \\
Tarsus length $(\mathrm{mm})$ & 30.59 & .26 & & 28.36 & .65 \\
Wing length $(\mathrm{mm})$ & 76.47 & 1.43 & & 66.59 & 2.15 \\
\hline
\end{tabular}

Note. $n=34$ spotless starling nestlings belonging to 17 nests. 


\section{Literature Cited}

Alonso-Álvarez C., S. Bertrand, B. Faivre, and G. Sorci. 2007. Increased susceptibility to oxidative damage as a cost of accelerated somatic growth in zebra finches. Funct Ecol 21:873-879. https://doi.org/10.1111/j.1365-2435.2007.01300.x.

Altieri F., C. Grillo, M. Maceroni, and S. Chichiarelli. 2008. DNA damage and repair: from molecular mechanisms to health implications. Antioxid Redox Signal 10:891-938. https:// doi.org/10.1089/ars.2007.1830.

Anderson H.L., I.E. Brodsky, and N.S. Mangalmurti. 2018. The evolving erythrocyte: red blood cells as modulators of innate immunity. J Immunol 201:1343-1351. https://doi.org /10.4049/jimmunol.1800565.

Baos R., R. Jovani, N. Pastor, J.L. Tella, B. Jiménez, G. Gómez, M.J. González, and F. Hiraldo. 2006. Evaluation of genotoxic effects of heavy metals and arsenic in wild nestling white storks (Ciconia ciconia) and black kites (Milvus migrans) from southwestern Spain after a mining accident. Environ Toxicol Chem 25:2794-2803. https://doi.org/10.1897/05-570R.1.

Beckman K.B. and B.N. Ames. 1998. The free radical theory of aging matures. Physiol Rev 78:547-581. https://doi.org /10.1152/physrev.1998.78.2.547.

Beuchat C.A. and C.R. Chong. 1998. Hyperglycemia in hummingbirds and its consequences for hemoglobin glycation. Comp Biochem Physiol A 120:409-416. https://doi.org/10.1016 /S1095-6433(98)10039-9.

Bitton P.P., R.D. Dawson, and E.L. O’Brien. 2006. Influence of intraclutch egg-mass variation and hatching asynchrony on relative offspring performance within broods of an altricial bird. Can J Zool 84:1721-1726. https://doi.org/10.1139/z06 -179 .

Blackburn E.H. and E.S. Epel. 2012. Telomeres and adversity: too toxic to ignore. Nature 490:169-171.

Boonekamp J.J., C. Bauch, E. Mulder, and S. Verhulst. 2017. Does oxidative stress shorten telomeres? Biol Lett 13:20170164. https://doi.org/10.1098/rsbl.2017.0164.

Boonekamp J.J., G.A. Mulder, H.M. Salomons, C. Dijkstra, and S. Verhulst. 2014. Nestling telomere shortening, but not telomere length, reflects developmental stress and predicts survival in wild birds. Proc R Soc B 281:20133287. https:// doi.org/10.1098/rspb.2013.3287.

Collins A.R., A.A. Oscoz, G. Brunborg, I. Gaivao, L. Giovannelli, M. Kruszewski, C. Smith, and R. Štětina. 2008. The comet assay: topical issues. Mutagenesis 23:143-151. https:// doi.org/10.1093/mutage/gem051.

Costantini D. 2016. Oxidative stress ecology and the d-ROMs test: facts, misfacts and an appraisal of a decade's work. Behav Ecol Sociobiol 70:809-820. https://doi.org/10.1007 /s00265-016-2091-5.

Coussens L.M. and Z. Werb. 2002. Inflammation and cancer. Nature 420:860-867.

Cram D.L., P. Monaghan, R. Gillespie, and T. Clutton-Brock. 2017. Effects of early-life competition and maternal nutrition on telomere lengths in wild meerkats. Proc R Soc B 284:20171383. https://doi.org/10.1098/rspb.2017.1383.
Criscuolo F., A. Cornell, S. Zahn, and T.D. Williams. 2019. Oxidative status and telomere length are related to somatic and physiological maturation in chicks of European starlings (Sturnus vulgaris). J Exp Biol 222:jeb20471. https://doi.org/10 $.1242 /$ jeb.204719.

Criscuolo F., P. Monaghan, L. Nasir, and N.B. Metcalfe. 2008. Early nutrition and phenotypic development: "catch-up" growth leads to elevated metabolic rate in adulthood. Proc R Soc B 275: 1565-1570. https://doi.org/10.1098/rspb.2008.0148.

David S.S., V.L. O'Shea, and S. Kundu. 2007. Base-excision repair of oxidative DNA damage. Nature 447:941-950.

Dickinson B.C. and C.J. Chang. 2011. Chemistry and biology of reactive oxygen species in signaling or stress responses. Nat Chem Biol 7:504-511. https://doi.org/10.1038/nchembio.607.

Dizdaroglu M. 1993. Quantitative determination of oxidative base damage in DNA by stable isotope-dilution mass spectrometry. FEBS Lett 315:1-6. https://doi.org/10.1016/0014-5793(93) 81120-O.

Dizdaroglu M. and P. Jaruga. 2012. Mechanisms of free radicalinduced damage to DNA. Free Radic Res 46:382-419. https:// doi.org/10.3109/10715762.2011.653969.

Dmitriew C.M. 2011. The evolution of growth trajectories: what limits growth rate? Biol Rev 86:97-116. https://doi .org/10.1111/j.1469-185X.2010.00136.x.

Drummond H. and C. Rodríguez. 2013. Costs of growing up as a subordinate sibling are passed to the next generation in blue-footed boobies. J Evol Biol 26:625-634. https://doi.org /10.1111/jeb.12087.

Eens M., V.L. Jaspers, E. Van den Steen, M. Bateson, C. Carere, P. Clergeau, D. Costantini, et al. 2013. Can starling eggs be useful as a biomonitoring tool to study organohalogenated contaminants on a worldwide scale? Environ Int 51:141-149. https://doi.org/10.1016/j.envint.2012.11.003.

Fenstad A.A., B.M. Jenssen, B. Moe, S.A. Hanssen, C. Bingham, D. Herzke, J.O. Bustnes, and A. Krokje. 2014. DNA double-strand breaks in relation to persistent organic pollutants in a fasting seabird. Ecotoxicol Environ Saf 106: 68-75. https://doi.org/10.1016/j.ecoenv.2014.04.020.

Finkel T. and N.J. Holbrook. 2000. Oxidants, oxidative stress and the biology of ageing. Nature 408:239-247.

Forbes S., S. Thornton, B. Glassey, M. Forbes, and N.J. Buckley. 1997. Why parent birds play favourites. Nature 390:351-352.

Freeman-Gallant C.R., J. Amidon, B. Berdy, S. Wein, C.C. Taff, and M.F. Haussmann. 2011. Oxidative damage to DNA related to survivorship and carotenoid-based sexual ornamentation in the common yellowthroat. Biol Lett 7:429-432. https://doi.org /10.1098/rsbl.2010.1186.

Friedberg E.C., G.C. Walker, W. Siede, and R.D. Wood, eds. 2006. DNA repair and mutagenesis. American Society for Microbiology, Washington, DC.

Galván I., A. Bonisoli-Alquati, S. Jenkinson, G. Ghanem, K. Wakamatsu, T.A. Mousseau, and A.P. Møller. 2014. Chronic exposure to low-dose radiation at Chernobyl favours adaptation to oxidative stress in birds. Funct Ecol 28:1387-1403. https://doi.org/10.1111/1365-2435.12283. 
Geiger S., M. Le Vaillant, T. Lebard, S. Reichert, A. Stier, Y. Le Maho, and F. Criscuolo. 2012. Catching-up but telomere loss: half-opening the black box of growth and ageing tradeoff in wild king penguin chicks. Mol Ecol 21:1500-1510. https://doi.org/10.1111/j.1365-294X.2011.05331.x.

Gil D., S. Alfonso-Iñiguez, L. Pérez-Rodríguez, J. Muriel, and R. Monclús. 2019. Harsh conditions during early development influence telomere length in an altricial passerine: links with oxidative stress and corticosteroids. J Evol Biol 32:111-125. https://doi.org/10.1111/jeb.13396.

Gil D., E. Bulmer, P. Celis, and M. Puerta. 2008. Increased sibling competition does not increase testosterone or corticosterone levels in nestlings of the spotless starling (Sturnus unicolor). Horm Behav 54:238-243. https://doi.org/10.1016 /j.yhbeh.2007.11.013.

Gormally B.M., R. Fuller, M. McVey, and L.M. Romero. 2019. DNA damage as an indicator of chronic stress: correlations with corticosterone and uric acid. Comp Biochem Physiol A 227:116-122. https://doi.org/10.1016/j.cbpa.2018.10.007.

Griebel I.A. and R.D. Dawson. 2018. Predictors of nestling survival during harsh weather events in an aerial insectivore, the tree swallow (Tachycineta bicolor). Can J Zool 97: 81-90. https://doi.org/10.1139/cjz-2018-0070.

Hall M.E., J.D. Blount, S. Forbes, and N.J. Royle. 2010. Does oxidative stress mediate the trade-off between growth and self-maintenance in structured families? Funct Ecol 24:365373. https://doi.org/10.1111/j.1365-2435.2009.01635.x.

Heuser V.D., V.M. De Andrade, A. Peres, L.M. de Braga, and J.A. Chies. 2008. Influence of age and sex on the spontaneous DNA damage detected by micronucleus test and comet assay in mice peripheral blood cells. Cell Biol Int 32: 1223-1229. https://doi.org/10.1016/j.cellbi.2008.07.005.

Hurd T.R. and M.P. Murphy. 2009. Biological systems relevant for redox signaling and control. Pp. 13-45 in C. Jacob and P.G. Winyard, eds. Redox signaling and regulation in biology and medicine. Wiley-VCH, Weinheim. https://doi.org /10.1002/9783527627585.ch2.

Iyama T. and D.M. Wilson. 2013. DNA repair mechanisms in dividing and non-dividing cells. DNA Repair 12:620-636.

Jimeno B. and D. Gil. 2015. Parent-absent calls are related to nestling reaction time and parental food allocation in the spotless starling. Behaviour 152:1413-1431. https://doi.org/10 .1163/1568539X-00003285.

Kuznetsova A., P.B. Brockhoff, and R.H.B. Christensen. 2015. Package lmerTest. R package version 2(0). https://cran.uib.no /web/packages/lmerTest/lmerTest.pdf.

Lindström J. 1999. Early development and fitness in birds and mammals. Trends Ecol Evol 14:343-348. https://doi.org /10.1016/S0169-5347(99)01639-0.

Loeb L.A. and B.D. Preston. 1986. Mutagenesis by apurinic/ apyrimidinic sites. Annu Rev Genet 20:201-230. https:// doi.org/10.1146/annurev.ge.20.120186.001221.

Lomax M.E., L.K. Folkes, and P. O’Neill. 2013. Biological consequences of radiation-induced DNA damage: relevance to radiotherapy. Clin Oncol 25:578-585. https://doi.org/10 $.1016 /$ j.clon.2013.06.007.
López-Otín C., M.A. Blasco, L. Partridge, M. Serrano, and G. Kroemer. 2013. The hallmarks of aging. Cell 153:1194-1217. https://doi.org/10.1016/j.cell.2013.05.039.

López-Rull I., P. Celis, and D. Gil. 2007. Egg colour covaries with female expression of a male ornament in the spotless starling (Sturnus unicolor). Ethology 113:926-933.

Lord C.J. and A. Ashworth. 2012. The DNA damage response and cancer therapy. Nature 481:287-294.

Mandal P.K., C. Blanpain, and D.J. Rossi. 2011. DNA damage response in adult stem cells: pathways and consequences. Nat Rev Mol 12:198-202.

Mangel M. and S.B. Munch. 2005. A life-history perspective on short- and long-term consequences of compensatory growth. Am Nat 166:E155-E176. https://doi.org/10.1086/444439.

Martín-Vivaldi M., M. Ruiz-Rodríguez, M. Méndez, and J.J. Soler. 2006. Relative importance of factors affecting nestling immune response differs between junior and senior nestlings within broods of hoopoes Upupa epops. J Avian Biol 37:467476.

Meitern R., E. Sild, M.A. Lind, M. Männiste, T. Sepp, U. Karu, and P. Hõrak. 2013. Effects of endotoxin and psychological stress on redox physiology, immunity and feather corticosterone in greenfinches. PLoS ONE 8:e67545. https://doi.org /10.1371/journal.pone.0067545.

Metcalfe N.B. and C. Alonso-Alvarez. 2010. Oxidative stress as a life-history constraint: the role of reactive oxygen species in shaping phenotypes from conception to death. Funct Ecol 24:984-996. https://doi.org/10.1111/j.1365-2435.2010.01750.x.

Mohanty J., E. Nagababu, and J.M. Rifkind. 2014. Red blood cell oxidative stress impairs oxygen delivery and induces red blood cell aging. Front Physiol 5:84. https://doi.org/10.3389 /fphys.2014.00084.

Monaghan P. 2007. Early growth conditions, phenotypic development and environmental change. Philos Trans R Soc B 363:1635-1645. https://doi.org/10.1098/rstb.2007.0011.

Moreno J., J.P. Veiga, P.J. Cordero, and E. Mínguez. 1999. Effects of paternal care on reproductive success in the polygynous spotless starling Sturnus unicolor. Behav Ecol Sociobiol 47:47-53. https://doi.org/10.1007/s002650050.

Morera D., N. Roher, L. Ribas, J.C. Balasch, C. Doñate, A. Callol, S. Boltaña, et al. 2011. RNA-Seq reveals an integrated immune response in nucleated erythrocytes. PLoS ONE 6:e26998. https:// doi.org/10.1371/journal.pone.0026998.

Muraki K., K. Nyhan, L. Han, and J.P. Murnane. 2012. Mechanisms of telomere loss and their consequences for chromosome instability. Front Oncol 2:135. https://doi.org /10.3389/fonc.2012.00135.

Muriel J., L. Pérez-Rodríguez, M. Puerta, and D. Gil. $2015 a$. Diverse dose-response effects of yolk androgens on embryo development and nestling growth in a wild passerine. J Exp Biol 218:2241-2249. https://doi.org/10.1242/jeb.118257.

Muriel J., P. Salmón, A. Nunez-Buiza, F. de Salas, L. PérezRodríguez, M. Puerta, and D. Gil. 2015b. Context-dependent effects of yolk androgens on nestling growth and immune function in chicks of a multi-brooded passerine. J Evol Biol 28:1476-1488. https://doi.org/10.1111/jeb.12668. 
Nakagawa S. and H. Schielzeth. 2010. Repeatability for Gaussian and non-Gaussian data: a practical guide for biologists. Biol Rev 85:935-956. https://doi.org/10.1111/j.1469-185X.2010 .00141.x.

Nettle D., P. Monaghan, W. Boner, R. Gillespie, and M. Bateson. 2013. Bottom of the heap: having heavier competitors accelerates early-life telomere loss in the European starling, Sturnus vulgaris. PLoS ONE 8:e83617. https://doi.org/10.1371/journal .pone.0083617.

Nettle D., P. Monaghan, R. Gillespie, B. Brilot, T. Bedford, and M. Bateson. 2015. An experimental demonstration that earlylife competitive disadvantage accelerates telomere loss. Proc $\mathrm{R}$ Soc B 282:20141610. https://doi.org/10.1098/rspb.2014.1610.

Neuenschwander S., M.W. Brinkhof, M. Kölliker, and H. Richner. 2003. Brood size, sibling competition, and the cost of begging in great tits (Parus major). Behav Ecol 14:457462. https://doi.org/10.1093/beheco/arg025.

Noguera J.C., M. Lores, C. Alonso-Álvarez, and A. Velando. 2011. Thrifty development: early-life diet restriction reduces oxidative damage during later growth. Funct Ecol 25:11441153. https://doi.org/10.1111/j.1365-2435.2011.01856.x.

Núñez de la Mora A., H. Drummond, and J.C. Wingfield. 1996. Hormonal correlates of dominance and starvation-induced aggression in chicks of the blue-footed booby. Ethology 102: 748-761. https://doi.org/10.1111/j.1439-0310.1996.tb01164.x.

Ostling O. and K.J. Johanson. 1984. Microelectrophoretic study of radiation-induced DNA damages in individual mammalian cells. Biochem Biophys Res Commun 123:291-298. https:// doi.org/10.1016/0006-291X(84)90411-X.

Passantino L., M.A. Massaro, F. Jirillo, D. Di Modugno, M.R. Ribaud, G. Di Modugno, G.F. Pssatino, and E. Jirillo. 2007. Antigenically activated avian erythrocytes release cytokinelike factors: a conserved phylogenetic function discovered in fish. Immunopharmacol Immunotoxicol 29:141-152. https:// doi.org/10.1080/08923970701284664.

Pérez-Rodríguez L., T. Redondo, R. Ruiz-Mata, C. Camacho, G. Moreno-Rueda, and J. Potti. 2019. Vitamin E supplementation - but not induced oxidative stress - influences telomere dynamics during early development in wild passerines. Front Ecol Evol 7:173. https://doi.org/10.3389/fevo.2019.00173.

Pérez-Rodríguez L., A.A. Romero-Haro, A. Sternalski, J. Muriel, F. Mougeot, D. Gil, and C. Alonso-Alvarez. 2015. Measuring oxidative stress: the confounding effect of lipid concentration in measures of lipid peroxidation. Physiol Biochem Zool 88:345351. https://doi.org/10.1086/680688.

R Development Core Team. 2019. R: a language and environment for statistical computing. R Foundation for Statistical Computing, Vienna. https://www.R-project.org/.

Reichert S. and A. Stier. 2017 Does oxidative stress shorten telomeres in vivo? a review. Biol Lett 13:20170463. https:// doi.org/10.1098/rsbl.2017.0463.
Rojas E., M.C. Lopez, and M. Valverde. 1999. Single cell gel electrophoresis assay: methodology and applications. J Chromatogr B 722:225-254. https://doi.org/10.1016/S0378-4347 (98)00313-2.

Salin K., S.K. Auer, A.M. Rudolf, G.J. Anderson, A.G. Cairns, W. Mullen, R.C. Hartley, C. Selman, and N.B. Metcalfe. 2015. Individuals with higher metabolic rates have lower levels of reactive oxygen species in vivo. Biol Lett 11: 20150538. https://doi.org/10.1098/rsbl.2015.0538.

Salomons H.M., G.V. Mulder, L. van de Zande, M.F. Haussmann, M.H. Linskens, and S. Verhulst. 2009. Telomere shortening and survival in free-living corvids. Proc R Soc B 276:31573165. https://doi.org/10.1098/rspb.2009.0517.

Scanes C. 2015. Blood. Pp. 167-185 in C. Scanes, ed. Sturkie's avian physiology. Academic Press, New York.

Singh N.P., M.T. McCoy, R.R. Tice, and E.L. Schneider. 1988. A simple technique for quantitation of low levels of DNA damage in individual cells. Exp Cell Res 175:184-191. https://doi.org/10.1016/0014-4827(88)90265-0.

Sokal R.R. and J.F. Rohlf. 1981. Biometry: the principles and practice of statistics in biological research. W.H. Freeman, San Francisco.

Starck J.M. and R.E. Ricklefs. 1998. Patterns of development: the altricial-precocial spectrum. Pp. 3-26 in J.M. Stark and R.E. Ricklefs, eds. Avian growth and development. Oxford University Press, New York.

Su T.T. 2006. Cellular responses to DNA damage: one signal, multiple choices. Annu Rev Genet 40:187-208. https://doi.org /10.1146/annurev.genet.40.110405.090428.

Surai P.F. 1999. Vitamin E in avian reproduction. Poultry Avian Biol Rev 10:1-60.

- 2002. Natural antioxidants in avian nutrition and reproduction. Nottingham University Press, Nottingham.

. 2016. Antioxidant systems in poultry biology: superoxide dismutase. J Anim Res Nutr 1:8. https://doi.org/10 .21767/2572-5459.100008.

Swenberg J.A., K. Lu, B.C. Moeller, L. Gao, P.B. Upton, J. Nakamura, and T.B. Starr. 2011. Endogenous versus exogenous DNA adducts: their role in carcinogenesis, epidemiology, and risk assessment. Toxicol Sci 120:S130-S145. https:// doi.org/10.1093/toxsci/kfq371.

Udroiu I. and A. Sgura. 2016. Genotoxic sensitivity of the developing hematopoietic system. Mutat Res 767:1-7. https:// doi.org/10.1016/j.mrrev.2015.12.001.

Verhulst S., A. Aviv, A. Benetos, G.S. Berenson, and J.D. Kark. 2013. Do leukocyte telomere length dynamics depend on baseline telomere length? an analysis that corrects for "regression to the mean." Eur J Epidemiol 28:859-866. https:// doi.org/10.1007/s10654-013-9845-4.

von Sonntag C. 2006. Free-radical-induced DNA damage and its repair. Springer, Berlin. 